\title{
Survey of Public Opinions in Areas Close to Hamaoka Power Station in Shizuoka
}

-Generational Differences in the Levels of Acceptance of Nuclear Power-

\author{
Tokoha University, Ryuzo Yamamoto
}

\begin{abstract}
A questionnaire survey was conducted to address various matters involving the use of nuclear power in four communities near the Hamaoka Nuclear Power Plant, which is located in Shizuoka Prefecture and operated by the Chubu Electric Power Company. Analysis of the nearly 7,600 responses has revealed generational differences in the levels of acceptance of nuclear power. The younger generations proved to be more pro-nuclear. Moreover, a higher share of respondents among the elderly was found to result in age bias. In fact, voices in favor of resuming the use of a nuclear power plant after completion of the due safety review outnumbered those against it when responses were weighted according to the actual age composition in Japan. This survey has also demonstrated what needs to be done to deepen our understanding of nuclear power. This first commentary reports the survey findings.
\end{abstract}

KEYWORDS: Hamaoka nuclear power plant, public acceptance of nuclear power, survey of public opinions, energy mix, climate change

\section{Introduction}

This questionnaire survey was inspired by papers that analyze responses to public opinion surveys on nuclear power in the United Kingdom and the United States. The Japanese media and municipalities tend to conduct questionnaire surveys on nuclear power mostly using simple yes-no questions, such as whether the respondents are in favor or against the resumption of nuclear power generation.

In the West, questionnaire surveys tend to consist of detailed questions aimed at, among other things, gauging the level of interest in environmental issues and energy security among the respondents. The author decided to conduct a survey in this manner rather than asking simple yes-no questions in order to weigh the responses based on the level of interest in energy security and global warming. The findings from this survey were expected to serve as a reference for the formulation of nuclear and energy policies.

The survey targeted communities in the city of Omaezaki, which hosts the Hamaoka Nuclear Power Plant operated by the Chubu Electric Power Company, as well as the three

DOI : 10.15669/fukushimainsights.Vol.3.191

(C) 2021 Atomic Energy Society of Japan. All rights reserved.

Originally published in Journal of the Atomic Energy Society of Japan (ISSN 1882-2606), Vol. 58, No. 6, p. 367-370 (2016)

in Japanese. (Japanese version accepted: March 7, 2016) 
neighboring cities of Kakegawa, Kikugawa, and Makinohara. Questionnaire surveys in the United States and the United Kingdom indicate a high degree of acceptance of nuclear power among the host communities, but this acceptance is not necessarily shared among neighboring communities. The survey was conducted to confirm whether, as expected, the same tendency could be observed in Japan.

Just under 40,000 questionnaires were distributed in the four target cities from mid to late November 2015. Approximately 7,600 responses had been collected by mid-December. The results from an analysis of these responses are reported in two commentaries. This commentary analyzes the implications of these responses and, based on the findings, the next commentary will identify issues that need to be considered while formulating policies on nuclear and other energy sources.

\section{Questionnaire Survey and Opponents of Nuclear Power}

A few days after the questionnaires were mailed out, a journalist from a newspaper publishing company known for its anti-nuclear stance phoned us to ask whether some of the questions were posed in an attempt to lead the respondents into supporting nuclear power. The topics addressed in the questions that the journalist mentioned are listed in Table 1. The questionnaires stated facts about Japan's energy self-sufficiency rate, the country's degree of dependence on oil and gas imports from Middle East, and the state of global warming as well as the increased purchasing of fuel and rising electricity prices since the shutdown of nuclear power plants. These factual explanations are intended to analyze differences in responses based on the level of interest in energy and environmental issues. If questions such as these could be considered as leading, it would be impossible to conduct surveys that include factual explanations.

After listening to our explanation, the journalist followed up by asking why anti-nuclear views are not included in the questionnaire. Obviously, neither anti-nuclear views nor pro-nuclear views are presented in this questionnaire since it is intended to find out the views of the respondents based on facts. Given this, we explained that pro-nuclear views are not presented either. On the contrary, only objective facts are stated in adherence with the spirit of the questionnaire survey. A few days later, opponents to nuclear power organized a press conference to protest against our allegedly leading survey. Rising electricity prices seem to be an inconvenient truth for some people who oppose nuclear energy.

Our laboratory received dozens of phone calls because we included the phone number so that respondents could contact us if they had any inquiries about the questionnaire. The inquiries were almost equally divided into questions related to the content of the questionnaire and opinions in favor or against nuclear power. Those who favored nuclear energy mostly appreciated that the questions were intended to capture views that are hard to classify with yes-no

Table 1 Survey topics related to energy and environmental issues

- Imports of fossil fuels

- Risks posed by the Strait of Hormuz

- Impact of global warming

- Discussions at the COP 21 climate talks

- Japan's greenhouse-gas emissions targets

- Additional fuel costs

- Rising electricity prices for households

- Rising electricity prices for industry 
questions. They encouraged us to conduct more extensive surveys in this manner.

Nuclear skeptics were divided into two groups. Some hung up after unilaterally accusing us of leading respondents to answer in favor of nuclear energy. Other self-declared opponents identified matters that were unclear in an honest effort to find out more about nuclear power. Their questions often stemmed from misunderstandings. Due consideration must be given to encouraging these people to acquire correct information and gain a deeper understanding of nuclear power.

\section{Perils of Public Opinion Surveys Conducted by the Media}

Most questionnaire surveys conducted by the media ask respondents if they are in favor or against the resumption of nuclear power generation. For instance, an article dated February 16, 2016 that appeared in the Asahi Shimbun, a nationwide major news paper, features a survey conducted from January 16 to 17 . Asked if the suspended operation of nuclear power plants should be resumed, $31 \%$ of respondents were in favor and $54 \%$ were opposed.

Our questionnaire included the same question. As the age composition of the survey respondents in Table 2 shows, the respondents were unevenly distributed among different age groups. In Japan, people aged 60 and above account for $32.6 \%$ of the population. More than half - or 53.1\% — of the respondents belonged to this age category. Figure 1 shows the overall share of each view after the responses have been adjusted in line with the latest population composition of Japan. Broken down by age group, the responses demonstrate that, with age, people develop a more negative attitude toward the resumption of nuclear power generation, even after the completion of a due safety review. Opposition is strongest among people in their 60s.

Making this adjustment based on Japan's population composition results in over 50\% of respondents being in favor of the resumption, a fact that demonstrates the perils of simply tallying the responses. The same problem may be affecting other questionnaire surveys conducted by the media ${ }^{(*)}$. The aforementioned survey by the Asahi Shimbun sought responses by calling randomly sampled phone numbers, but it is important to note that few young people have landline phones in their homes nowadays. Moreover, only 1,943 persons (about 50\%) of the owners of the 3,909 sampled household phone numbers responded to the survey. As you

Table 2 Response rate and Japan's population composition broken down by age group

\begin{tabular}{|lll|}
\hline Age group & $\begin{array}{l}\text { Percentage of total } \\
\text { responses [\%] }\end{array}$ & $\begin{array}{l}\text { Percentage of total } \\
\text { population [\%] }\end{array}$ \\
\hline Teens & 0.5 & 9.3 \\
\hline $20 \mathrm{~s}$ & 1.8 & 10.3 \\
\hline $30 \mathrm{~s}$ & 4.5 & 13.1 \\
\hline $40 \mathrm{~s}$ & 10.2 & 14.2 \\
\hline $50 \mathrm{~s}$ & 19.9 & 12.1 \\
\hline $60 \mathrm{~s}$ & 36.5 & 14.4 \\
\hline $70 \mathrm{~s}$ and older & 26.6 & 18.2 \\
\hline Total & 100.0 & 91.6 \\
\hline & $\begin{array}{l}\text { Note: The population composition is based on materials obtained from } \\
\text { the Ministry of Internal Affairs and Communication (2013) }\end{array}$ \\
\hline
\end{tabular}

\footnotetext{
* As we later discovered, the results from surveys conducted by the media were also adjusted according to the population
} composition. Consequently, the relevant discussion is to be removed. 


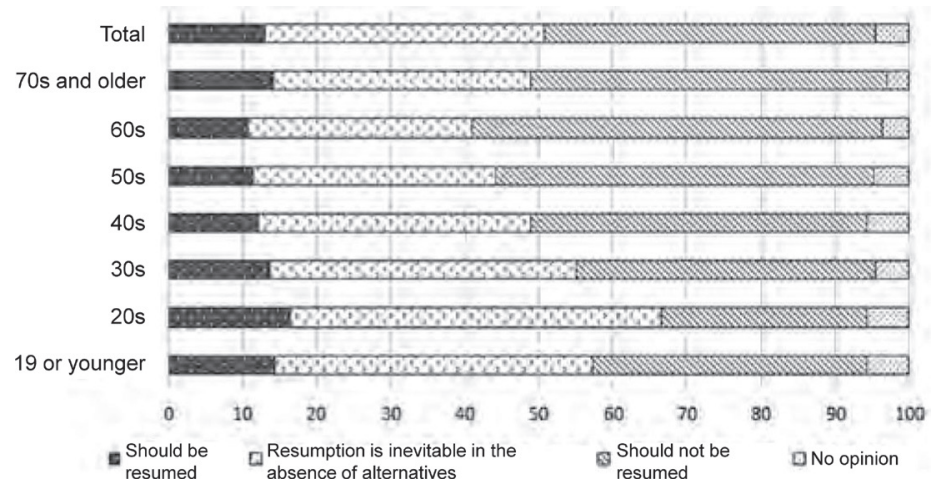

Figure 1 Stance on resumption broken down by age group

Note: The overall proportion was adjusted based on the population composition according to the Ministry of Internal Affairs and Communication.

Table 3 Opinions on possible resumption broken down by gender

\begin{tabular}{|lccc|}
\hline & Total & Male & Female \\
\hline Responses & 7513 & 4970 & 2461 \\
\hline $\begin{array}{l}\text { Should be resumed } \\
\begin{array}{l}\text { Resumption is inevitable in } \\
\text { the absence of alternatives }\end{array}\end{array}$ & 33.5 & 15.5 & 5.4 \\
\hline $\begin{array}{l}\text { Should not be resumed } \\
\text { No opinion }\end{array}$ & 50.3 & 43.6 & 33.2 \\
\hline
\end{tabular}

Note: Raw data without adjustment by age group. The total figure includes 83 respondents who declined to specify their gender.

might imagine, the majority of the respondents represented senior age groups.

In conducting their opinion surveys, the media must keep up with the times and advances in information technologies. Simply tallying the responses obtained via outdated landline phones will almost certainly cause the results to be heavily biased by the views of the elderly. It is more prudent to suspect the presence of age bias in a public opinion survey if a breakdown of the respondents by age group is not presented.

Admittedly, fewer women responded to our survey, with a ratio of roughly two males to one female. Furthermore, women tend to be relatively more opposed to the resumption of nuclear power generation, as shown in Table 3. Adjusting the results for age and gender will probably result in a slightly lower share of respondents being in favor of the resumption. In addition, the responses vary depending on the respondents' places of residence and occupations.

\section{How Places of Residence and Occupations Influence the Level of Acceptance for the Resumption of Nuclear Power Generation}

The locations of the four target cities are presented in Figure $\mathbf{2}$ along with the preliminary 
population counts from the census conducted on October 1, 2015. The response rates in the local populations were 3.7\% in Kakegawa, 3.1\% in Omaezaki, 3.3\% in Kikugawa, and 3.5\% in Makinohara. As a host municipality, Omaezaki had a slightly lower response rate but it was still much the same as that of the neighboring cities.

Opinions diverged between Omaezaki and the three neighboring cities regarding the possible resumption of nuclear power generation, as expected based on earlier studies conducted in other countries that pointed to greater support for nuclear power in host communities. As the responses broken down by city in Figure 3 show, negative views have a relatively higher share without adjustment by age group.

The survey also gauged the level of interest in energy and environmental issues. In response to a question asking if they realized that the shutdown of nuclear power plants had led to a rise in fuel costs, a higher share of respondents from Omaezaki responded that they were aware of this compared to their counterparts in the three other cities. This fact suggests that host communities tend to be more interested in rises in fuel costs caused by the shutdown of a nuclear power plant.

At times, newspersons have told us that they agonize over how much they can touch on the issue of the possible resumption of nuclear power generation given that most of their viewers are homemakers opposed to nuclear energy. As mentioned earlier, our survey also confirmed

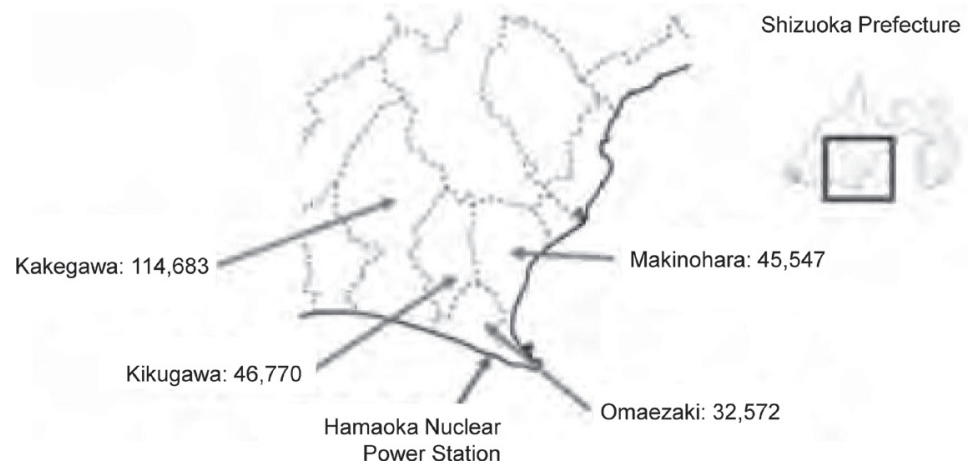

Figure 2 Map of area around the Hamaoka Nuclear Power Plant Note: The local population is indicated after each city name.

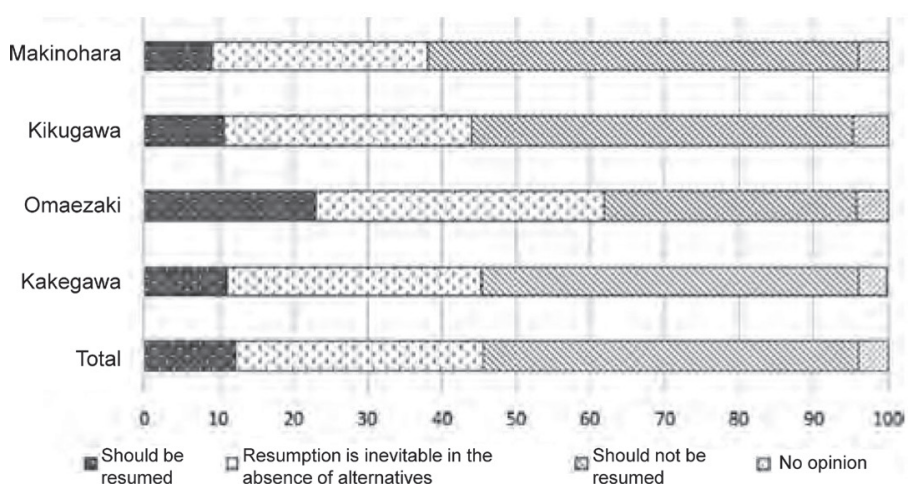

Figure 3 Opinions on possible resumption in each city

Note: Raw data without adjustment by age group. The total figure includes 83 respondents who declined to specify their gender. 


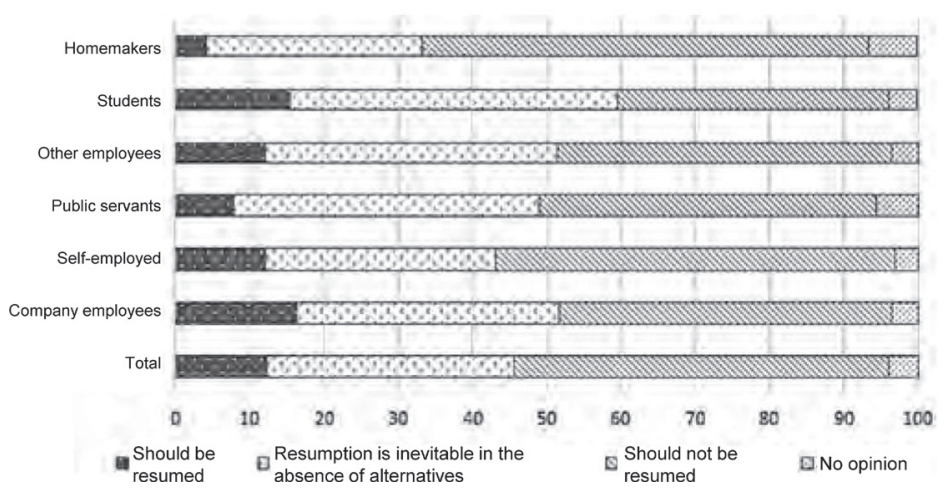

Figure 4 Opinions on possible resumption broken down by occupation Note: Raw data without adjustment broken down by age group.

that women tend to be more opposed to the resumption.

The greatest share of respondents to this survey had no occupation, most probably due to their ages. This share of roughly $29 \%$ was followed by the following: company employees (24\%), self-employed (16\%), homemakers (14\%), and public servants (4\%). The combination of responses indicating that nuclear power plants should be resumed or that resumption is inevitable in the absence of alternatives outnumbered those expressing opposition to resumption among company employees, public servants, other employees such as group staff, and students. Homemakers were the most opposed to the resumption, as shown in Figure 4.

Respondents who are more interested in energy or environmental issues tend to be relatively more in favor of the resumption of nuclear power generation than those who are less interested in such issues. This analysis will be discussed further in the next commentary.

\section{Opinions on the Additional Construction of Nuclear Power Plants}

The government of Japan has announced a goal of supplying between 20 and $22 \%$ of its electricity from nuclear energy by 2030 , along with 22 to $24 \%$ from renewable energy, $3 \%$ from oil-fired thermal power, $26 \%$ from coal-fired thermal power, and $27 \%$ from LNG. This target for the energy mix of power sources is combined with a goal for 2030 of enhancing the country's energy efficiency by $35 \%$.

These goals embody the national government's commitment to reducing greenhouse gas emissions by $26 \%$ by 2030 from the 2013 level under the Framework Convention on Climate Change. A total target share of $44 \%$ was presumably assigned to nuclear and renewable energy as low-carbon sources of power, which still required energy savings of $35 \%$ to fulfill the Japanese commitment. It is safe to say that these goals were calculated backwards from the commitment to reduce greenhouse gas emissions.

The proportion between the two low-carbon sources of power seems to have been decided based on estimates of electricity prices. An increase in the share of renewable energy encouraged by a feed-in tariff would inevitably push up electricity prices. Most probably, the proportion of nuclear and renewable energy was decided based on the estimated share of renewables that would still not push up electricity prices. 
An increase in the share of nuclear energy from the current level to between 20 to $22 \%$ would require the operation of some nuclear power plants to be extended from 40 to 60 years and some existing plants to be replaced with new plants. Otherwise, some new plants may need to be additionally constructed. Responses to questions on the additional construction and replacement of nuclear power plants are shown in Figure 5. An almost similar trend as that associated with age groups can be observed with respect to stances on the possible resumption of nuclear power generation after safety reviews. Nonetheless, fewer respondents support the additional construction or replacement of plants as compared to their resumption.

Similarly, relative to the level of support for the resumption of nuclear power generation, fewer respondents favored the government policy of setting a target share of $20 \%$ for nuclear power. The latter share was similar to the shares observed for favorable stances toward the additional construction or replacement of nuclear power plants. It will be difficult to achieve the goal of reducing greenhouse gas emissions without public support for the government policy of increasing the share of nuclear power to $20 \%$. This weak level of support stems from low trust in the national government.

Figure 6 presents the level of trust in the national government among respondents from the four target cities. The number of respondents in Omaezaki who expressed the view that the

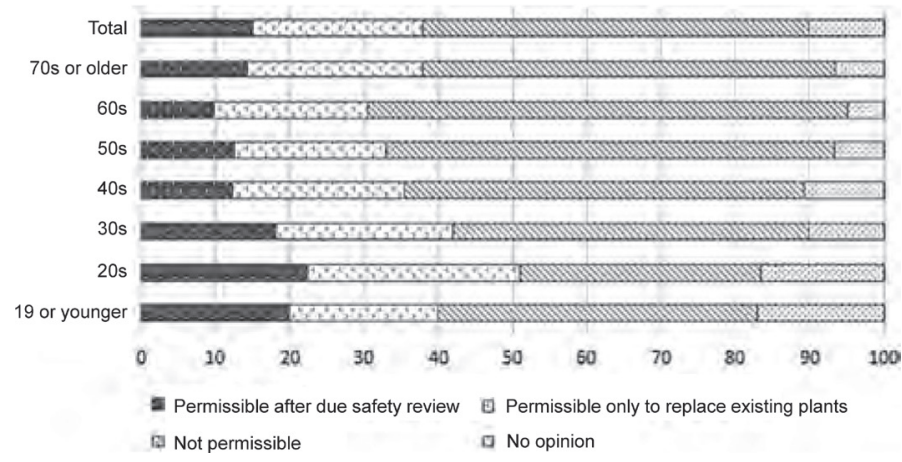

Figure 5 Stances on additional construction broken down by age group

Note: The overall proportion was adjusted based on the age composition according to the Ministry of Internal Affairs and Communication

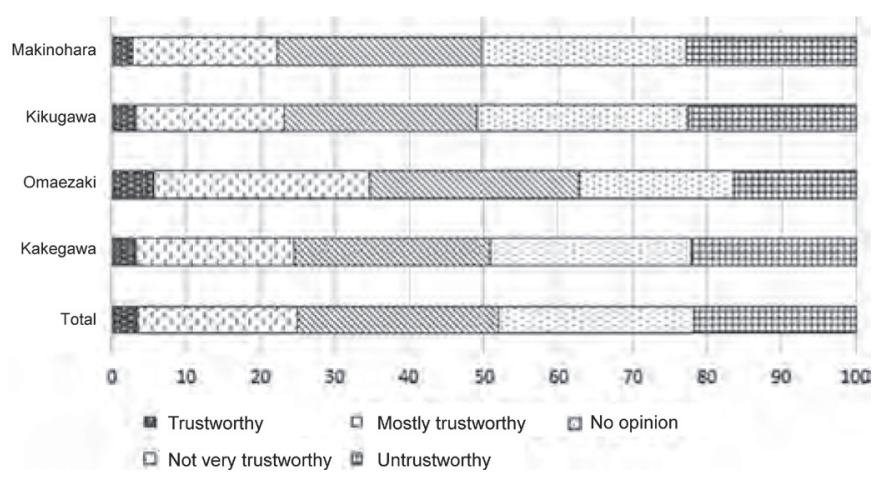

Figure 6 Level of trust in the national government 
national government is trustworthy or mostly trustworthy exceeded that of respondents in the other three cities. Nonetheless, the number of these respondents was lower than the number of those who expressed the view that the government is not very trustworthy or untrustworthy.

\section{Trust in the Government Must be Enhanced}

The government has announced an energy mix target for power sources in 2030 . Nonetheless, steps to increase the share of nuclear power from the current level to from 20 to $22 \%$ have not been clarified. It takes more than 10 years to construct an additional plant or replace an existing plant. Consequently, as soon as the necessary power output from nuclear power plants for 2030 is specified, the government must immediately clarify how the target can be achieved. Otherwise, it will be difficult to achieve the targets for greenhouse gas emissions and the energy mix of power sources. Unless this process is clarified, trust in the government will remain low.

Respondents from the four cities indicated a relatively higher level of trust toward the Chubu Electric Power Company compared to their level of trust toward the national government and its nuclear policy. In particular, the power utility company was considered trustworthy or mostly trustworthy among $47.2 \%$ of respondents from Omaezaki. This share far exceeds the $29.3 \%$ of respondents who regarded the utility company as not very trustworthy or untrustworthy.

The relatively higher level of trust toward the utility company compared to the government could conceivably result from familiarity with company employees in the local communities who have personalities that inspire confidence. The utility company can also offer more indepth explanations to local residents.

Therefore, face-to-face explanations seem to be the key to gaining trust toward nuclear power. What types of explanations should be provided? The next commentary will discuss the relevant findings from our questionnaire survey. 